\title{
Predicting freakish sea state with an operational third-generation wave model
}

\author{
T. Waseda ${ }^{1}$, K. In ${ }^{1, *}$, K. Kiyomatsu ${ }^{1}$, H. Tamura ${ }^{2}$, Y. Miyazawa ${ }^{2}$, and K. Iyama ${ }^{1, * *}$ \\ ${ }^{1}$ Graduate School of Frontier Sciences, University of Tokyo, Kashiwa, Japan \\ ${ }^{2}$ Japan Marine and Earth, Science and Technology, Yokohama, Kanagawa ,Japan \\ *now at: Automobile R\&D Center, Honda Automobile, Tochigi, Japan \\ ** now at: R\&D Center, JR East Group, Saitama, Japan \\ Correspondence to: T. Waseda (waseda@k.u-tokyo.ac.jp)
}

Received: 24 August 2013 - Published in Nat. Hazards Earth Syst. Sci. Discuss.: 6 November 2013

Revised: 2 October 2013 - Accepted: 2 March 2014 - Published: 22 April 2014

\begin{abstract}
The understanding of freak wave generation mechanisms has advanced and the community has reached a consensus that spectral geometry plays an important role. Numerous marine accident cases were studied and revealed that the narrowing of the directional spectrum is a good indicator of dangerous sea. However, the estimation of the directional spectrum depends on the performance of the thirdgeneration wave model. In this work, a well-studied marine accident case in Japan in 1980 (Onomichi-Maru incident) is revisited and the sea states are hindcasted using both the DIA (discrete interaction approximation) and SRIAM (Simplified Research Institute of Applied Mechanics) nonlinear source terms. The result indicates that the temporal evolution of the basic parameters (directional spreading and frequency bandwidth) agree reasonably well between the two schemes and therefore the most commonly used DIA method is qualitatively sufficient to predict freakish sea state. The analyses revealed that in the case of Onomichi-Maru, a moving gale system caused the spectrum to grow in energy with limited downshifting at the accident's site. This conclusion contradicts the marine inquiry report speculating that the two swell systems crossed at the accident's site. The unimodal wave system grew under strong influence of local wind with a peculiar energy transfer.
\end{abstract}

\section{Introduction}

A number of ship accidents in the northwestern Pacific Ocean, especially in the sea east of Japan, were reported decades ago. The mysterious sea is coined "the Dragon's Triangle" mimicking the famous "Bermuda Triangle" in the Atlantic Ocean (Berlitz, 1989). During World War II, Admiral Halsey and his fleet sailed into the heart of Typhoon Cobra in the North Pacific, and lost three destroyers (Drury and Clavin, 2007). Recently Atsukawa (1999) analysed the meteorological conditions during this incident and suggested that the vessel might have encountered a wave of over $30 \mathrm{~m}$ in height (Fig. 1). Although this description is rather speculative, Atsukawa did make numerous interesting observations: the ship had encountered waves over $30 \mathrm{~m}$, which were followed by $28 \mathrm{~m}$ waves; the Kuroshio Current is present; and the bow of the ship had surfaced. These observations are related to the formation of a wave group, wave-current interaction and a slamming load. Undoubtedly, Atsukawa's observation is influenced by the well-known and well-studied marine accident near Japan, the Onomichi-Maru incident (Yamamoto et al., 1983). The incident is memorable because of the famous picture of the ship without the bow (Fig. 2). Because of lack of knowledge about freak/rogue waves at that time, the cause of the incident was mistakenly attributed to a high wave called the Sankaku-nami in Japanese or triangular wave, which suggests a crossing of large swells. We will show in this study that this was not the case and the directional spectrum was unimodal at the time of the incident. 
Historical incidents of the freak wave or the rogue wave are well documented in the text book by Kharif, Pelinovsky and Sulnyev (2010). The large waves that appear in the ocean unexpectedly are named differently, each representing one of the characters of the freak wave: giant wave, mad-dog wave, wall of water, holes in the sea, three sisters, pyramidal waves, etc. Scientists and engineers define them as waves that are "higher than twice the significant wave height" and are "isolated". For linear- and narrow-banded random waves, the distribution of wave height is approximately Rayleigh like (Longuett-Higgins and Cart-Wright, 1953) and therefore the appearance of waves over twice the significant wave height is about once every 3000 waves. Inevitably, the encounter of ships with freak and giant waves is rare, but Kharif and Pelinovsky (2003) report that during the period 1969199422 super-carrier ships and 525 lives in total may have been lost due to freak waves in the Atlantic and the Pacific oceans. Nine of the accidents occurred in the Dragon's Triangle, including the two large, Japanese carrier ships: the Bolivar-Maru and the Onomichi-Maru. More recent incidents of fishing boats, ferry boats and the Onomichi-Maru are documented in Waseda et al. (2012). Out of seven incidents, five occurred when the directional spectrum narrowed. None of the incidents had direct evidence of the ship encountering the freak wave, but the freakish-sea index which maps the dimension of the directional spectrum indicated a dangerous sea state for those cases.

The freakish-sea index maps the trajectory of the directional spreading $\left(\sigma_{\theta}\right)$ and frequency bandwidth $\left(Q_{\mathrm{p}}\right)$ and was successfully used in the study of the Suwa-Maru incident by Tamura et al. (2009) and of the Onomichi-Maru incident by In et al. (2009). What the freakish-sea index indicates is the temporal change of the geometry of the directional spectrum. In most of the incidents studied by Waseda et al. (2012), the freakish-sea index was changing rapidly in time. Furthermore, in some cases, the incidents occur exactly when the freakish-sea index indicated the narrowest directional spectrum.

Numerous "freak wave indices" are suggested. Attributing the modulational instability of the long-crested waves for the formation of large-amplitude waves, Onorato et al. (2001) and Janssen (2003) independently introduced a parameter that compares the relative magnitude of nonlinearity and dispersion. Those parameters were called the Ursell number and the Benjamin-Feir index respectively. The latter terminology is used more often in recent literatures. These studies were experimentally extended to include the effect of directional spreading of the wave spectrum by Waseda (2006). However, earlier works already indicated evidences that for realistic directional spreading, the occurrence probability of freak waves is small (Onorato et al., 2002; Soquet-Juglard et al., 2005). In turn, the freak wave occurrence becomes high when the bandwidth of the wave spectrum is narrow (Toffoli et al., 2008; Onorato et al., 2009a, b; Waseda et al., 2009; Mori et al., 2011; Xiao et al., 2013). The conclusion de- duced from these experimental works were validated by observations indicating that under certain meteorological conditions the probability of freak wave occurrence will increase (Waseda et al. 2011).

In this paper, the wave field during the time of the accident of the Onomichi-Maru will be hindcasted with an operational wave model (WAVEWATCH III). The comparison of the model results with the sea states described in the official report of the marine accident inquiry were presented earlier by In et al. (2009). A brief overview of the OnomichiMaru incident and the hindcast simulation will be provided in Sect. 2. The comparison of the spectral evolution and the deduced freakish-sea index will be compared between the DIA (discrete interaction approximation) simulation and SRIAM (Simplified Research Institute of Applied Mechanics) simulation in Sects. 3 and 4. The possible cause of the freakish sea state under moving gale conditions will be discussed in Sect. 5.; and the Conclusion follows.

\section{Hindcast simulation of the Onomichi-Maru accident}

The Japanese bulk-carrier Onomichi-Maru was built in 1965 $(200 \mathrm{~m}, 60000 \mathrm{t})$. On 30 December 1980, during a voyage carrying a full load of coal from the United States to Japan, she encountered an extremely high wave and as a result of the slamming impact lost her bow. The fact that a super-carrier ship over $200 \mathrm{~m}$ was split into two bodies by the force of a wave's impact came to a shock for the Japanese Ministry of Transportation. A committee was organized to investigate the cause of the accident, concurrently with the marine accident inquiry. The committee concluded that the impact of the slam was too strong for her body to remain intact and the Onomichi-Maru was broken into two (Yamamoto et al., 1983). The estimated height of the wave was about $20 \mathrm{~m}$. The committee reported that at the time of the accident, steady swell came from the west with $8-9 \mathrm{~m}$ significant wave height and $12 \mathrm{~s}$ wave period, and another relatively unsteady swell came from the west-northwest with $3.8-6.2 \mathrm{~m}$ significant wave height and $12 \mathrm{~s}$ wave period. The committee concluded that the former steady swell caused the pitching motion of the ship, and an unlucky superposition of the second swell made an extreme wave which caused severe slamming. However, our simulation result shows that this was not the case.

We conducted a three-tiered nested-wave hindcast simulation covering the period from 1 December 1980 to 10 January 1981 by an operational third-generation wave model WAVEWATCH III (Tolman 2002). The first level (nest1) covers the whole Pacific Ocean at $1^{\circ}$ resolution $\left(95^{\circ} \mathrm{E}-70^{\circ} \mathrm{W},-75^{\circ} \mathrm{S}-75^{\circ} \mathrm{N}\right)$, the second level (nest2) covers the northwestern Pacific Ocean with $0.25^{\circ}$ resolution $\left(135^{\circ}-180^{\circ} \mathrm{E}, 22^{\circ}-47^{\circ} \mathrm{N}\right)$, and the last level (nest 3$)$ covers an area around the accident's site with $0.125^{\circ}$ resolution $\left(150^{\circ}-160^{\circ} \mathrm{E}, 26^{\circ}-36^{\circ} \mathrm{N}\right)$. The topography of each area was specified by ETOPO2 (NOAA). As the wind data, we used the JRA-25 (Japanese Re-Analysis 25 years) data of the 
Table 1. Summary of conditions of the Onomichi-Maru accident from the marine accident inquiry report (JST Japan standard time).

\begin{tabular}{|c|c|c|c|c|}
\hline \multicolumn{5}{|c|}{ The details of the accident } \\
\hline Date & \multicolumn{4}{|c|}{ 1980-12-30-14:30 (JST) } \\
\hline Locale & \multicolumn{4}{|c|}{$156^{\circ} 11^{\prime} \mathrm{E}, 31^{\circ} 0^{\prime} \mathrm{N}$} \\
\hline \multicolumn{5}{|c|}{ The particulars of Onomichi-Maru } \\
\hline Length & & & $216.40 \mathrm{~m}$ & \\
\hline Breadth & & & $31.7 \mathrm{~m}$ & \\
\hline Draft & & & $17.3 \mathrm{~m}$ & \\
\hline \multicolumn{5}{|c|}{ The sea state } \\
\hline & Height & Period & Length & Dir.(from) \\
\hline Swell 1 & $8-9 \mathrm{~m}$ & $12 \mathrm{~s}$ & $150-180 \mathrm{~m}$ & $\mathrm{~W}$ \\
\hline Swell 2 & $4-6 \mathrm{~m}$ & $12 \mathrm{~s}$ & $225-284 \mathrm{~m}$ & WNW \\
\hline Wind wave & $4 \mathrm{~m}$ & $8 \mathrm{~s}$ & no data & WSW \\
\hline Wind & \multicolumn{3}{|c|}{ Lv.8 Beaufort rank $=>17.2--20.7 \mathrm{~m} \mathrm{~s}^{-1}$} & WSW \\
\hline
\end{tabular}

Japan Meteorological Agency, which is $1.25^{\circ}$ resolution at $3 \mathrm{~h}$ intervals covering most areas of the globe. The model setting is detailed in In et al. (2009) and will be briefly summarized here: the number of directions was set to 24 (spaced by $15^{\circ}$ ) for SRIAM and 36 (spaced by $10^{\circ}$ ) for DIA; the number of frequencies was set to 25 levels, with the incremental factor of 1.1 in the frequency range $0.0412-0.4056 \mathrm{~Hz}$, or 1.08 in the range of $0.0412-0.2611 \mathrm{~Hz}$. The source terms of the WAVEWATCH III (Tolman-Chalikov source terms) were selected by benchmarking the model setting against the fetch law with an ideal wind condition (Iyama 2007).

The nonlinear wave-wave interaction term (Snl) is calculated by both the DIA method (Hasselmann et al., 1985) and the SRIAM method (Komatsu and Masuda, 1996). The SRIAM method approximates the Hasselman's collision integral (Hasselmann, 1963) with 20 optimized combinations of resonant quartets instead of one in DIA. The SRIAM method was implemented in realistic simulations for the first time by Tamura et al. (2008, 2009 and 2010), demonstrating that the directional spectrum under rapidly changing wind conditions and the spectral tail are better resolved by the SRIAM method. In Tamura et al. (2009), spectral evolution of swell and wind-wave interaction was hindcasted for the Suwa-Maru No. 58 incident (June 2008) using SRIAM Snl. In this study, we have made hindcast simulation with both DIA and SRIAM Snl and compared the spectral evolutions. These model results were validated by Iyama (2007) and In (2009) with observational data of NOWPHAS (Nationwide Ocean Wave information network for Ports and HArbors; Port and Airport Research Institute in Japan) and the drifting GPS buoy.

The sea state during the accident and the particulars of Onomichi-Maru from the marine inquiry report are summarized in Table 1. Swells 1 and 2 were suggested to be the main cause of the accident. The committee report states that

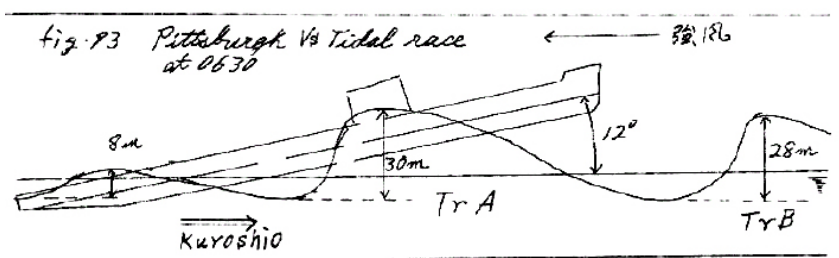

Fig. 1. A schematic of the Pittsburgh encountering giant wave of $30 \mathrm{~m}$ (reproduced from Atsukawa, 1999).

swell 1 from the west caused the pitching motion of the ship, and an unlucky superposition of the swell 2 from the westnorthwest made an extreme wave of $20 \mathrm{~m}$ which caused a severe slamming impact. However, from the wave field map of Otsubo (1983), the main locations of these swells seem far away from the actual accident's site (Fig. 3 left). This historical hand-drawn wave-field map is likely based on the second generation wave model, which was the most reliable at that time (Tomita, 2009). The swell 1 is indicated by a horizontal arrow and the swell 2 by an oblique arrow in the south. The accident's location is marked by the cross.

These swell systems are indeed well resolved in our simulation (Fig. 3). In the north of the accident's site (solid square), the wave (12-12.5 s) which might correspond to swell 1 is propagating from the west, and in the southwest of the accident's site, the wave (11.5-12 s) which might correspond to swell 2 is propagating from the west-northwest. At the accident's location, a wave $(12.41 \mathrm{~s}, 8.22 \mathrm{~m})$ was propagating eastward, slightly oriented towards the south (rotated $5.36^{\circ}$ to the south, Fig. 3). In an area south of $35^{\circ} \mathrm{N}$, the directions of wind and wave (swell 1) are almost the same (Fig. 4). Along the latitude of the accident's site $\left(31^{\circ} \mathrm{N}\right)$, the wave directions are nearly constant (eastward) and the peak period becomes longer as the waves propagate to the east. The westerly winds were sustained for about 5 days before the time of the accident.

The significant wave height and the three parameters relevant for freak wave prediction are mapped in Fig. 5. A region with high nonlinearity (steepness), narrow directional spreading and reduced dispersion (narrow frequency bandwidth) is found in a large area stretching from east to west in which the accident's site is located at the centre ${ }^{1}$. The area

\footnotetext{
${ }^{1}$ Wave steepness $\left(a_{k}\right): a_{k}=\frac{\pi}{\sqrt{2}} \times \frac{H_{\mathrm{s}}}{L_{\mathrm{m}}}$

Frequency peakedness $\left(Q_{\mathrm{p}}\right)($ Goda, 1970) :$$
Q_{\mathrm{p}}=2 m_{0}^{-2} \int_{0}^{\infty} \mathrm{d} \sigma \sigma\left[\int_{0}^{2 \pi} F(\sigma, \theta) \mathrm{d} \theta\right]^{2} \text { where } m_{0}=
$$$$
\int_{0}^{2 \pi} \int_{0}^{\infty} F(\sigma, \theta) \mathrm{d} \sigma \mathrm{d} \theta
$$$$
\text { Directional spreading }\left(\sigma_{\theta}\right) \text { (Kuik et al., 1988): }
$$$$
\sigma_{\theta}=\left[2\left\{1-\left(\frac{a^{2}+b^{2}}{m_{0}^{2}}\right)^{\frac{1}{2}}\right\}\right]^{\frac{1}{2}} \text { where } a=
$$$$
\int_{0}^{2 \pi} \int_{0}^{\infty} \cos (\theta) F(\sigma, \theta) \mathrm{d} \sigma \mathrm{d} \theta, b=\int_{0}^{2 \pi} \int_{0}^{\infty} \sin (\theta) F(\sigma, \theta) \mathrm{d} \sigma \mathrm{d} \theta
$$ 


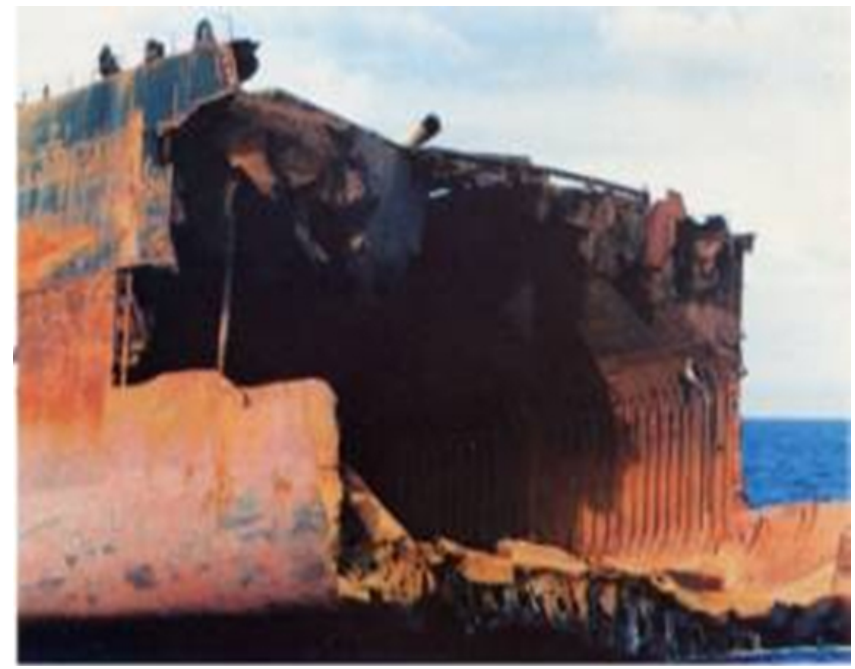

Fig. 2. An image of the Onomichi-Maru without a bow.

represents where the probability of freak wave occurrence is high. The temporal evolution of the wind speed, significant wave height, spectral peak period, steepness, frequency bandwidth $Q_{\mathrm{p}}$ and directional spreading $\sigma_{\theta}$, are plotted in Fig. 6. A gale of over $14 \mathrm{~m} \mathrm{~s}^{-1}$ started on 27 December and reached its maximum when the accident occurred on $30 \mathrm{De}-$ cember. The $Q_{\mathrm{p}}$ increased within a day before the accident, and $\sigma_{\theta}$ decreased continuously during the gale condition. Despite $a k$ remained relatively unchanged, the directional spectrum narrowed and became narrowest when the accident occurred. Therefore, the Onomichi-Maru may have sailed through the centre of a dangerous sea where freak wave occurrence was high. Furthermore, the evolution of the directional spectrum reveals that the coexistence of the two swell systems, as suggested by the inquiry committee, is highly unlikely at the accident's location (Sect. 3).

\section{Spectral evolution}

The spectral evolution at the test site will be investigated based on the third-generation wave model outputs. Evolution of the directional spectrum will be described for both DIA and SRIAM computations (Sect. 3.1). In Sect. 3.2, the source terms will be studied in detail comparing the two schemes.

\subsection{Directional spectrum}

The wave-energy density at the time of the accident is unimodal and is unequivocally reproduced by both DIA and SRIAM hindcast simulations (Figs. 7 and 8, lower left). The two swell systems as indicated by the incident report are not present in these simulation results. The projection of the directional spectrum to the frequency and directional domain are calculated as follows:

$$
\begin{aligned}
& F(\sigma)=\int_{0}^{2 \pi} F(\sigma, \theta) \mathrm{d} \theta, \\
& F(\theta)=\int_{0}^{\infty} F(\sigma, \theta) \mathrm{d} \sigma .
\end{aligned}
$$

The $F(\sigma, \theta), F(\sigma)$ and $F(\theta)$ from six different times before the accident $(72,48,24,12$, and $6 \mathrm{~h})$ and at the time of the accident are shown for both DIA and SRIAM computations (Figs. 7, 8). Both the frequency and the directional wave spectra are unimodal and narrow, and do not indicate a multiple-wave system or a mixed-sea condition. The peak of the energy spectrum occurs at $0.0803 \mathrm{~Hz}$ (the wave period about $12.54 \mathrm{~s}$ or $240 \mathrm{~m}$ in wavelength). The energy rapidly grew within $72 \mathrm{~h}$ before the accident with a slight downshifting, and veered from west-southwest to west-northwest (Fig. 7, DIA). The directional shifting, however, is not as swift in the directional spectrum from the SRIAM calculation (Fig. 8) which shows small peaks at both $-10^{\circ}$ (westnorthwest) and $20^{\circ}$ (west-southwest). Although these peaks might appear to correspond to the two swell systems (Table 1), they are not swells as they both grew rapidly in time and are strongly affected by local wind.

The evolution of the directional spectrum, however, is atypical of a wind sea. In typical wind seas, the energy increase is associated with spectral downshifting, i.e. follows the fetch law. It appears that the peak of the frequency spectrum downshifts only slightly while the energy increases rapidly. From 29 to 30 December, the significant wave height increased more than $20 \%$ (Fig. 6). For wind seas in local equilibrium, the wave period should then increase following the Toba's law (Toba, 1973) but the actual increase seems to saturate (see Appendix A for further analysis). Thus, it seems that in the last $24 \mathrm{~h}$ before the accident, the evolution of the wave field was unusual. This tendency is evident in both DIA and SRIAM computations, and the frequency spectrum is even narrower with SRIAM. Comparing the frequency spectra $48 \mathrm{~h}$ before and after the accident, the rapid narrowing of spectral bandwidth in just a few days is rather remarkable.

Overall, we can conclude that there was only one wave system at the accident's site and it is strongly influenced by the local wind. Because the value of the directional spreading $\sigma_{\theta}$, was minimum at the accident's time (Fig. 6), the sea condition was likely not a crossing sea as conjectured in the accident report. With a relatively narrow directionality and frequency bandwidth, the possibility of freak wave occurrence might have increased, and caused the accident.

\subsection{The source functions}

As the wind sea grows under constant wind forcing, the energy is transferred from the waves in the frequency range 

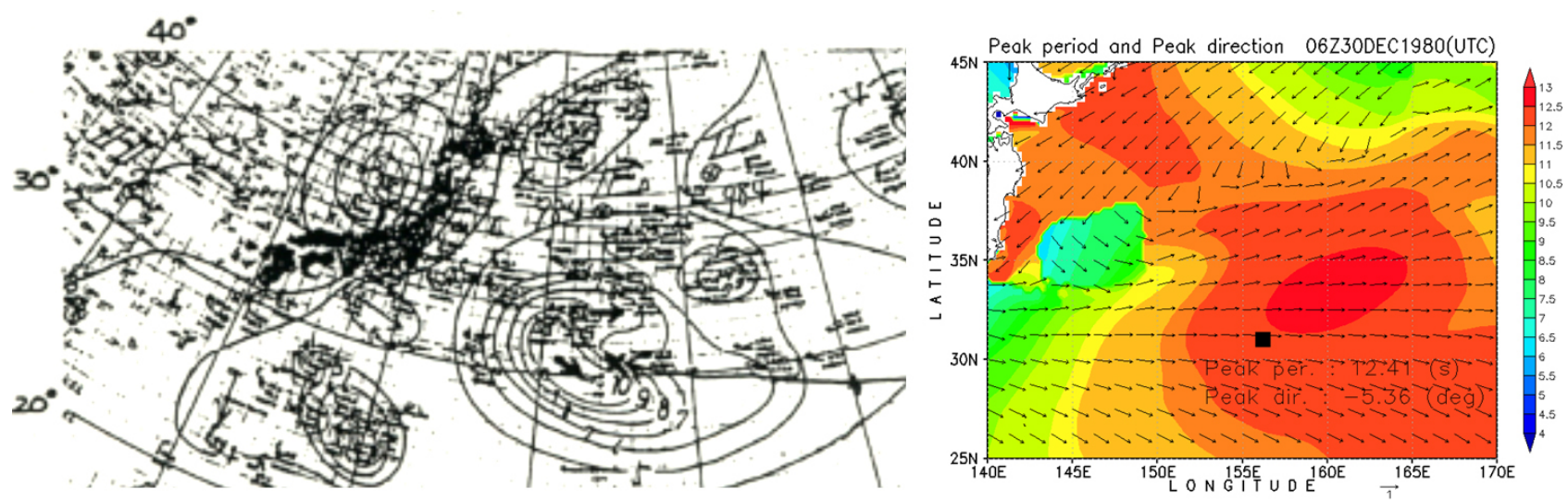

Fig. 3. The historical wave-field map (contours are significant wave height, arrows indicate direction of waves, and cross the marks the accident's location) reproduced from Otsubo (1983) (left), and the peak period and direction from this simulation (right; colour shading is the peak period, and the arrows show the wave propagation direction).
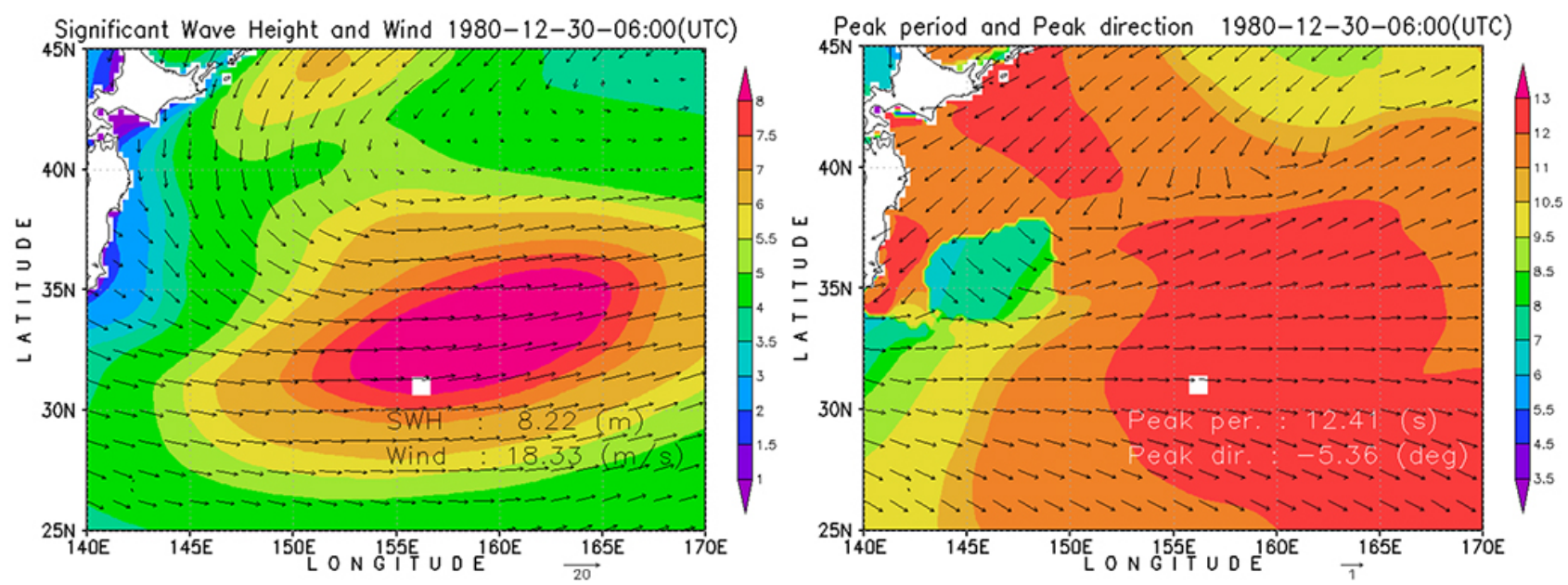

Fig. 4. (Left) The field data of significant wave height (Hs, contour) and wind speed vector when the accident occurred. White square is the accident's site. The data is from the second-level field (nest2). Wind vectors are subsampled at every 5 grids. (Right) The field data of peak period (contour) and peak direction (arrows) when the accident occurred. White square is the accident's site.

higher than the peak of the spectrum to the frequency range lower than the peak and to the spectral tail (Hasselman et al., 1985). As a result, the spectral peak downshifts. The transfers of energy among spectral components occur due to four wave-resonant interactions and the shape of the transfer function depends on the spectral geometry. The growth of fetchlimited or duration-limited wind seas under constant wind forcing is thus characterized by this typical nonlinear transfer function Snl and the associated self-similar spectrum.

However, under changing wind conditions, the directional spectrum deviates from the standard self-similar spectral shape and likewise the Snl. Rapid narrowing of the frequency spectrum with limited spectral peak downshifting is a remarkable feature during the Onomichi-Maru accident (Figs. 7, 8). Thus a peculiar shape of $\mathrm{Snl}$ is expected. The temporal evolution of $\mathrm{Snl}$ in frequency domain is depicted in Fig. 9. From 72 to $48 \mathrm{~h}$ before the accident, the peak of the spectrum gradually downshifts (Figs. 7, 8) and so is the peak of the Snl. However, from $24 \mathrm{~h}$ before the accident, the energy level of the peak builds up while the peak of the Snl is more or less fixed in frequency. Another notable feature of the Snl is the large negative value in the range of around $0.075-0.18 \mathrm{~Hz}(1-2.5$ times the spectral peak frequency) and the large positive value in the range of around $0.18-0.3 \mathrm{~Hz}$ (2.5-4 times the spectral peak frequency). Thus, a large part of the spectral energy is transferred to both the peak of the spectrum and to the tail of the spectrum as a result of nonlinear wave-wave interaction.

However, the spectral shape at frequencies higher than twice the peak $(-0.15 \mathrm{~Hz})$ remains more or less unchanged. Tamura et al. (2010) has shown that in the operational wave model, the nonlinear source term annuls the imbalance of the 

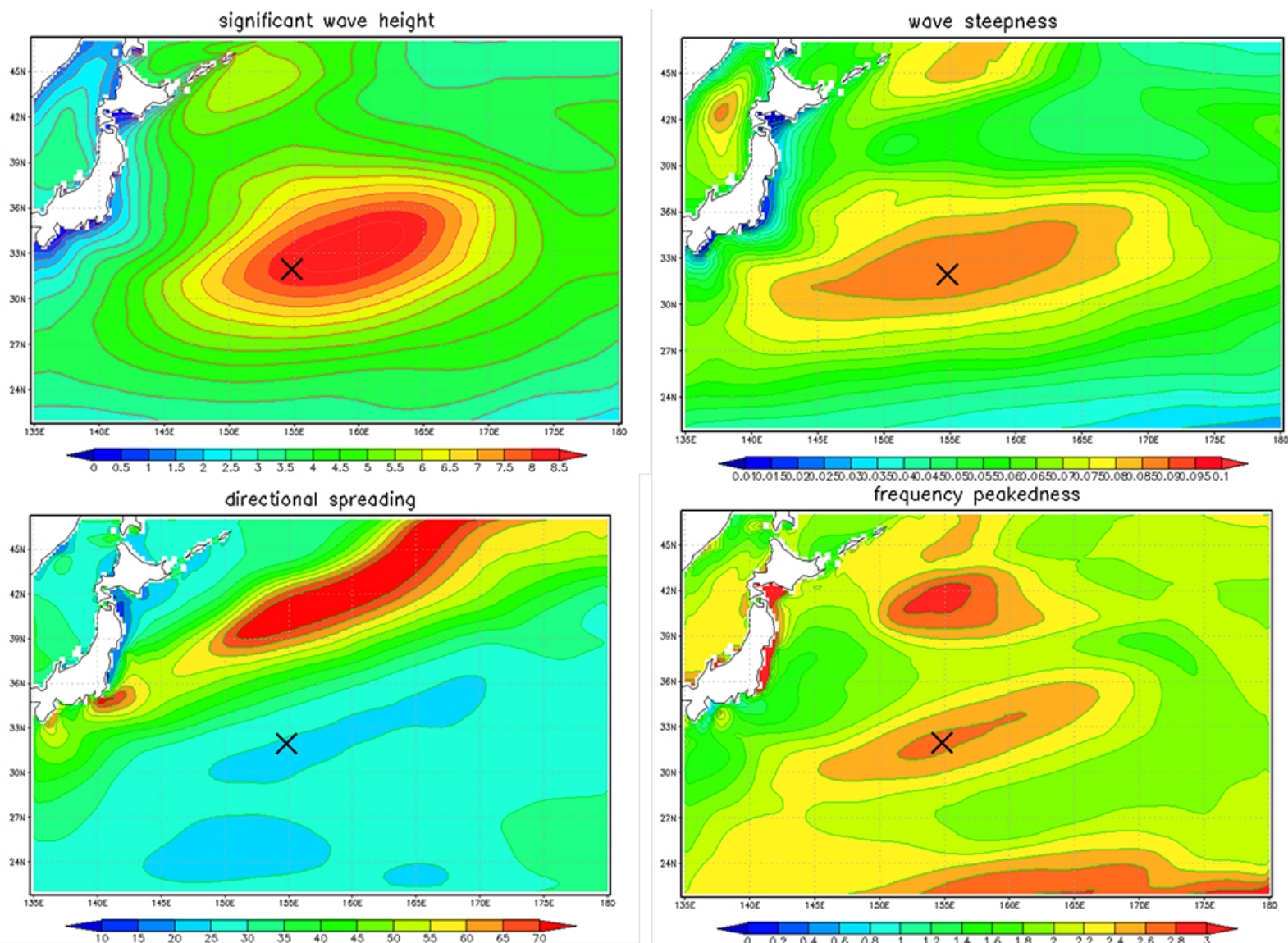

Fig. 5. Significant wave height (top left), wave steepness (top right), directional spreading (bottom left) and frequency peakedness (bottom right) at the time of the Onomichi-Maru accident (30 December 1980). The crosses denote the accident's location.
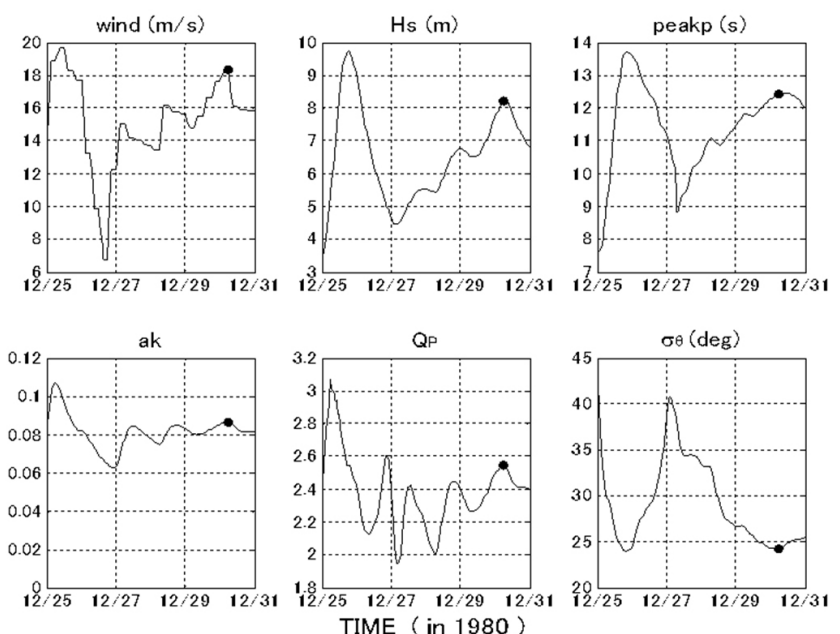

Fig. 6. Time series of sea state parameters from 25 December to 31 December in 1980 at the accident's site $\left(156.1^{\circ} \mathrm{E}, 31.0^{\circ} \mathrm{N}\right)$; wind speed, significant wave height $\left(H_{\mathrm{s}}\right)$, wave steepness $\left(a_{k}\right)$, peak period (peakp), frequency peakedness $\left(Q_{\mathrm{p}}\right)$, and directional spreading $\left(\sigma_{\theta}\right)$. The red dot marks the accident's time. energy input and dissipation and therefore the equilibrium spectral tail remains unchanged. Therefore, the large Snl values at frequency ranges higher than twice the spectral peak are not an indication of spectral change. Indeed a large part of the wind input energy is redistributed elsewhere by nonlinear transfer (Fig. 10). Most likely, the energy is transferred to the frequency range of the spectral peak, but at oblique angles. The tendency to broaden the spectrum at the peak is more prominent with the SRIAM computation (compare Figs. 7 and 8). The spectrum is quite narrow in frequency but relatively broad in direction. This broadening is a consequence of active energy transfer among spectral components. Therefore it is apparent that the wave system is not a simple linear superposition of the two swell systems. A few days before the accident, the wave field was more or less bimodal (note the two wave systems are different from swell 1 and 2). As the gale system developed, the unimodal directional spectrum developed around $0.1 \mathrm{~Hz}$ and gradually downshifted to around $0.07 \mathrm{~Hz}$ where the spectral energy developed rapidly. The spectral geometry will be characterized by two parameters, directional spreading and frequency bandwidth, i.e. the freakish-sea index, in the next section. 

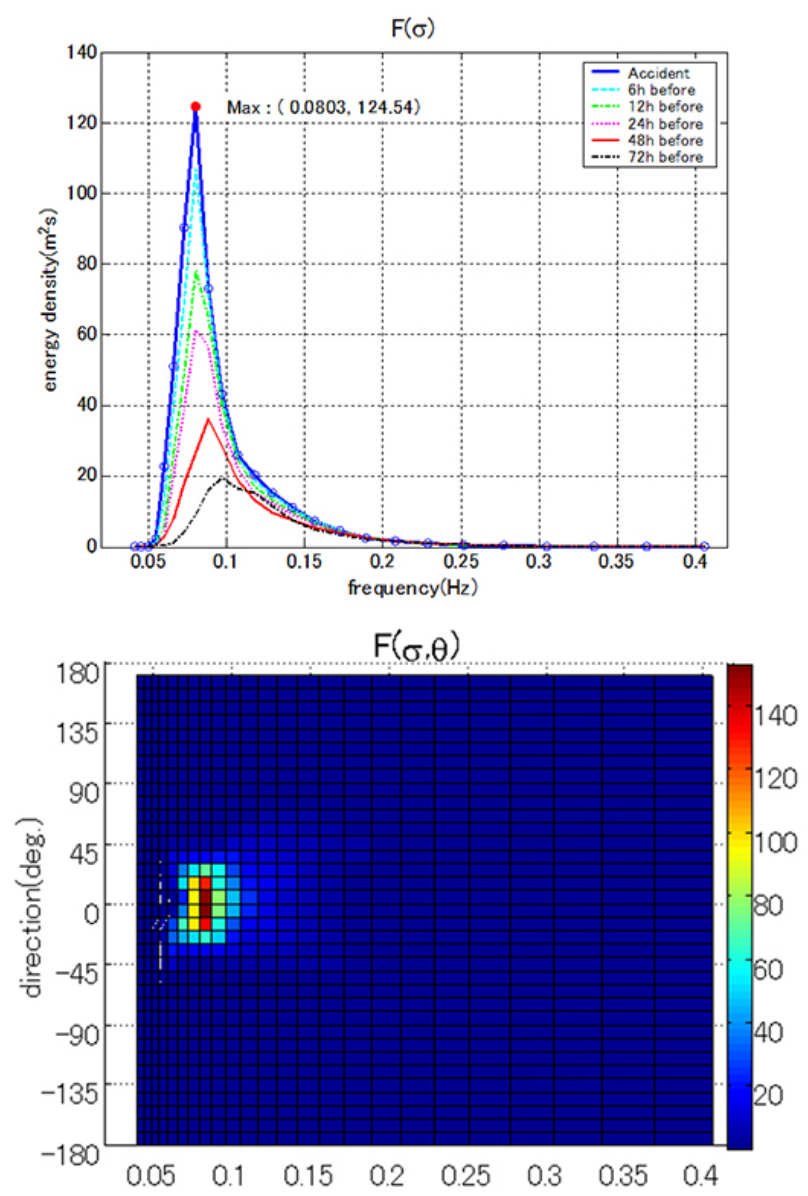
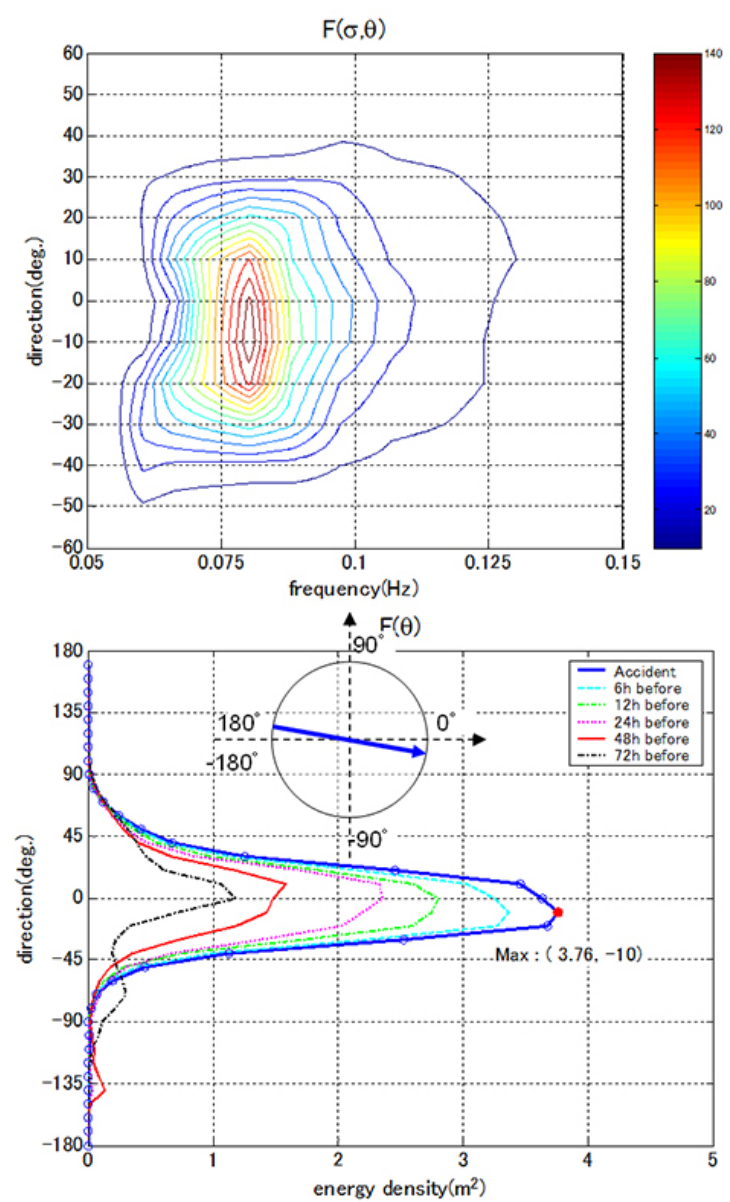

Fig. 7. Directional spectrum at the time of the accident (lower left) and the spectrum enlarged around the peak (upper right). The evolution in time of the spectrum projected on the frequency domain (upper left) and on the directional domain (lower right) is shown from 3 days before the accident to the time of the accident. The simulation was made using DIA.

\section{Freakish-sea index}

In the case of the Onomichi-Maru accident, the directional spectrum rapidly narrowed in frequency and direction in $24 \mathrm{~h}$. A number of marine accidents occur in similar situations in which the sea states rapidly changed. Those incidents are described in Waseda et al. (2012) and Tamura et al. (2009). None of these marine accidents have solid evidence of freak wave occurrence but these case studies suggest that an operational wave model is useful in providing a warning criterion for ships navigating in open ocean. A visualized risk index of freak waves will be useful and we proposed to use the joint-probability-density function (JPDF) of the directional spreading $Q_{\mathrm{p}}$ and the frequency peakedness $\sigma \theta$ as an indicator of the likelihood of freak waves (In et al., 2009; Tamura et al., 2009). The idea of the freakish-sea index is to visualize the development of its spectrum in the $Q_{\mathrm{p}}$ and $\sigma_{\theta}$ domain. In the case of Suwa - maru incident, Tamura et al., (2009) showed nicely that the spectrum narrowed rapidly in less than $6 \mathrm{~h}$ as a result of interaction of background swell and wind sea. The spectrum thus developed from a bimodal state to unimodal state. In the case of Onomichi-Maru, the rapid change of $Q_{\mathrm{p}}$ was associated with local development of the wave system.

These spectral developments might be affected by the setting of the operational model. In the case of Onomichi-Maru incident, both the DIA and SRIAM nonlinear source terms were used. As illustrated in Sect. 3, the use of the SRIAM method slightly broadened the spectrum in direction but narrowed the spectrum in frequency. Let us now compare the performance of DIA and SRIAM simulations in expressing the freakish-sea index (Fig. 11). Apparently, the timing of the accident is unequivocally represented at the turning point of the $Q_{\mathrm{p}}$ and $\sigma_{\theta}$ trajectories; i.e. both simulations commonly indicate that the accident occurred when the directional spectrum was narrowest within the 4 days. The values of both $Q_{\mathrm{p}}$ and $\sigma_{\theta}$ are about the same despite the subtle difference in the directional distribution at the peak frequency (Figs. 7, 8). At other times, the SRIAM simulation tends to show slightly broader spectrum in direction but the frequency bandwidth 

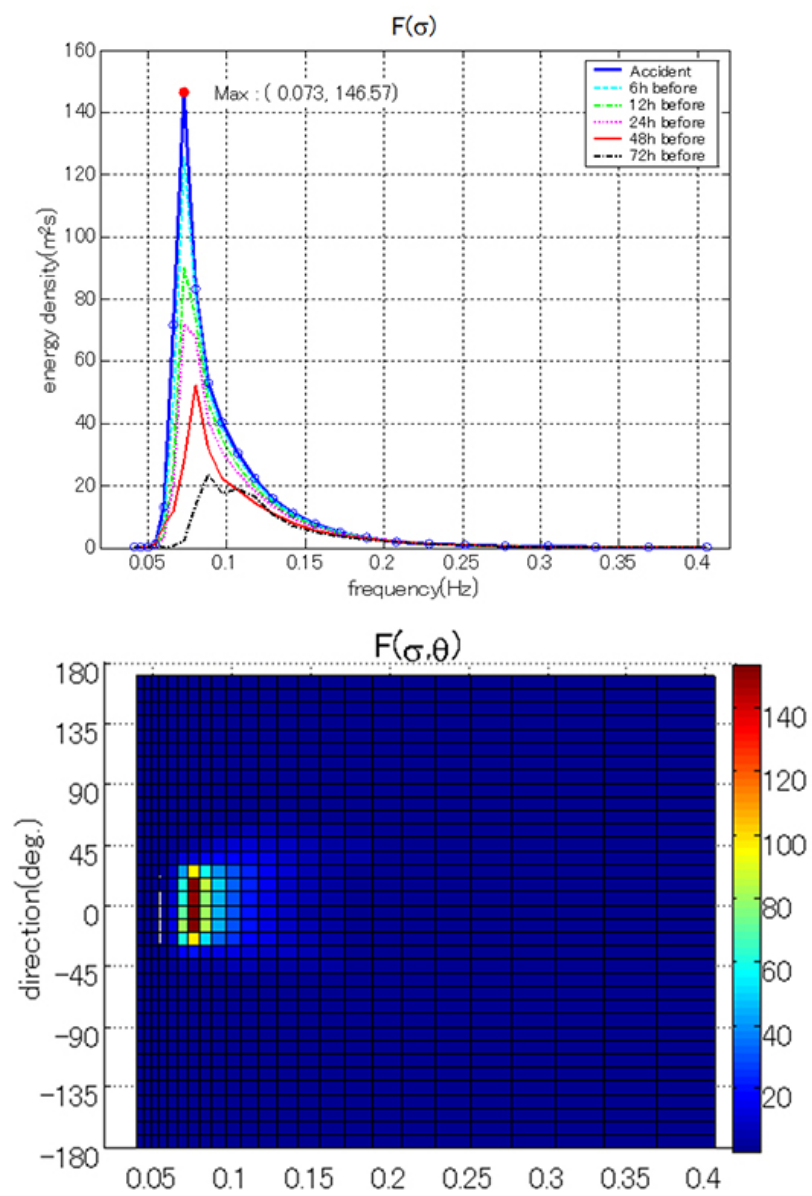

Fig. 8. Same as Fig. 7 but for the simulation made using SRIAM.

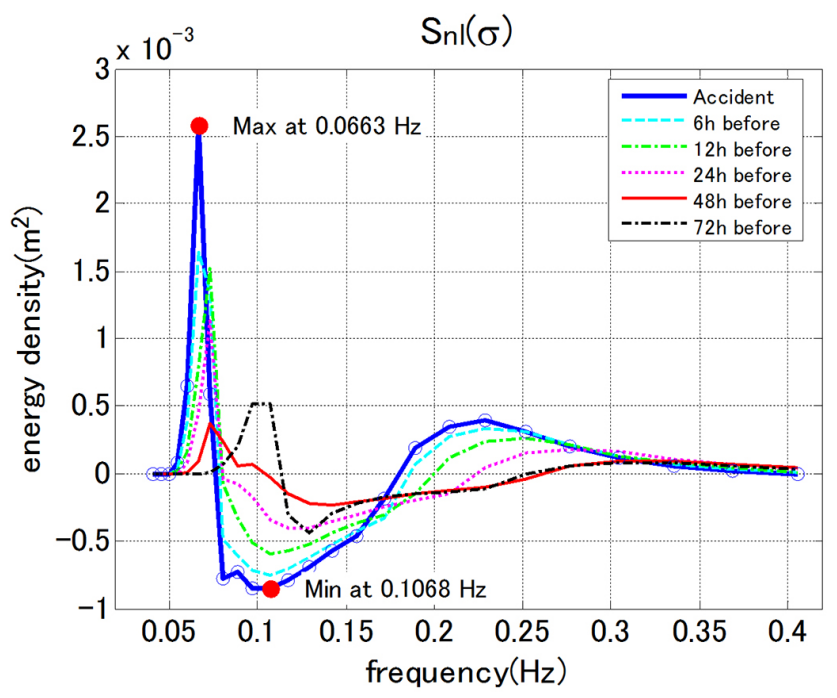

Fig. 9. The nonlinear transfer function corresponding to the SRIAM simulation result shown in Fig. 8. The results shown are for 72, 48, 24,12 , and $6 \mathrm{~h}$ before the accident and at the time of the accident.
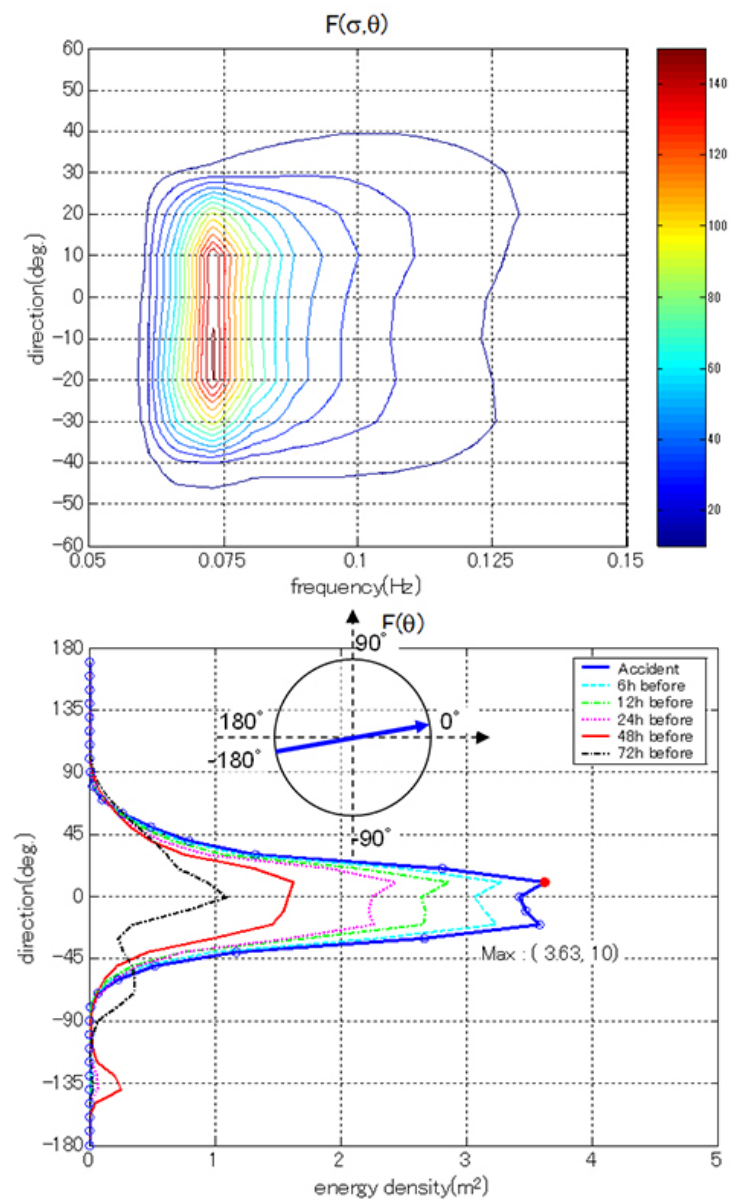

seem to agree. Qualitatively, the two diagrams convey the same message that the accident occurred at the turning point of the $Q_{\mathrm{p}}$ and $\sigma_{\theta}$ trajectory. For operational use, DIA is 20 times faster than SRIAM. Our comparison suggests that the DIA simulation is sufficient to provide qualitatively correct information useful for the warning criterion.

\section{Wind-sea development under changing wind field}

The change of the wave spectrum in time observed at a fixed location is determined by not only the source functions but also the propagation term. Classical fetch laws are obtained only for those cases where either the tendency term can be neglected (fetch-limited) or the propagation term can be neglected (duration-limited). In realistic cases, wind fields are changing in both time and space so that both the tendency and the propagation terms are important. It is therefore not surprising if the overall change in the spectral shape deviates from ideal cases of fetch- or duration-limited wind sea. Nevertheless, it is of interest to find out how the wind field changed in the Onomichi-Maru accident case. 

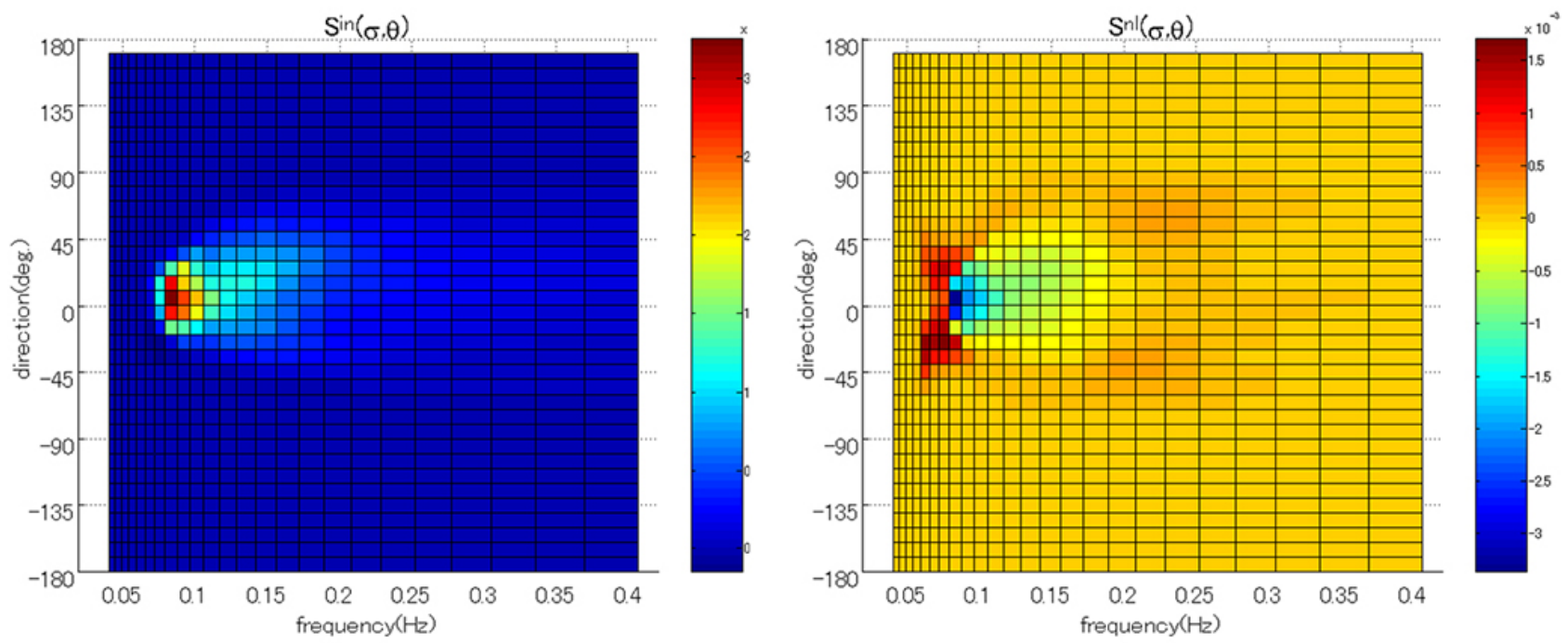

Fig. 10. The wind input source function (left) and the nonlinear transfer function of the SRIAM simulation (right) at the time of the accident.
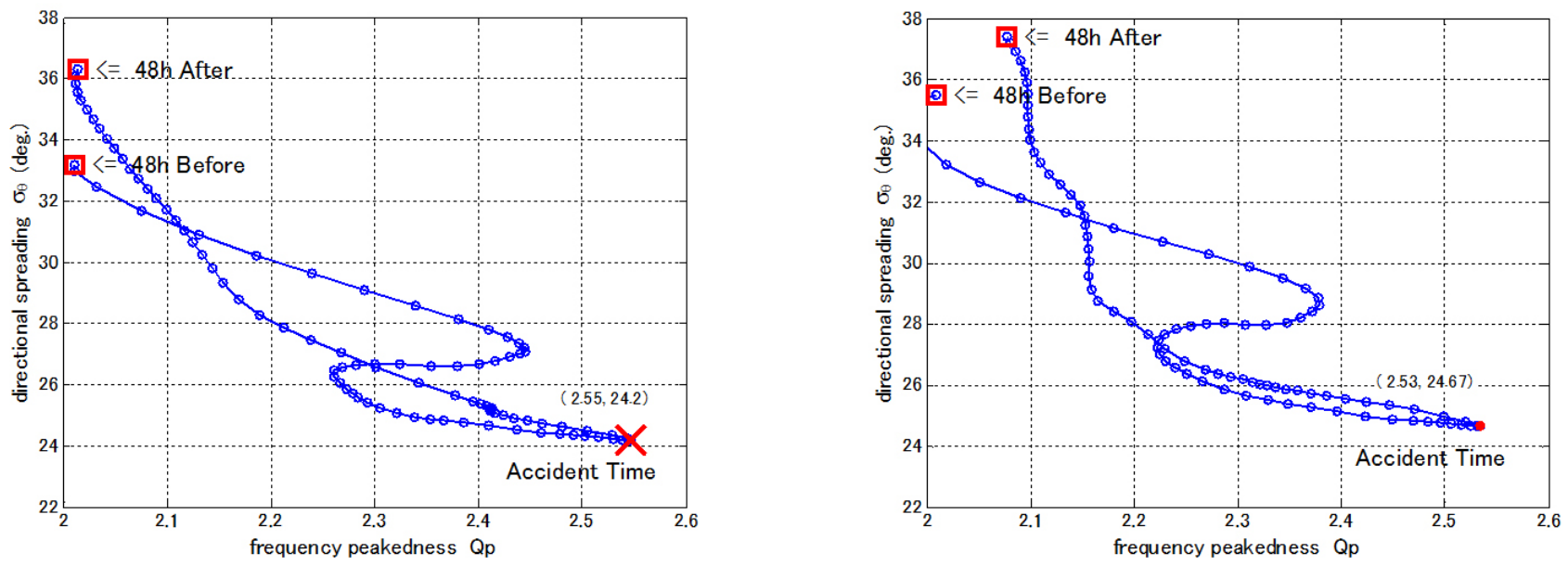

Fig. 11. 2-D scatter plot of frequency peakedness and directional spreading by $1 \mathrm{~h}$ interval for $48 \mathrm{~h}$ before and after the accident (left DIA, right SRIAM). Red cross and red point indicate the accident's time.

The wind speed and wind vectors of 29 December 12:00 and 30 December 00:00 UTC (Universal Time Coordinated) are presented in Fig. 12. A strong gale system with maximum velocity close to $20 \mathrm{~m} \mathrm{~s}^{-1}$ covered a large area east of Japan $(3000 \mathrm{~km}$ by $1000 \mathrm{~km})$ and moved $1000 \mathrm{~km}$ to the east in $12 \mathrm{~h}$. The gale system itself strengthening and the change of wind speed observed at the accident's location can be attributed to its eastward movement. Therefore, initially the wind speed is decaying to the east along the $31^{\circ} \mathrm{N}$ latitude (28 December 06:00 UTC) but as the gale system moves towards the east, the wind speed is increasing to the east along $31^{\circ} \mathrm{N}$ (12/29 18:00 UTC); Fig. 13. When the accident occurred (30 December 06:00 UTC), the peak of the gale system reached the accident's location and the highest wind speed was recorded. Evolution of the wave spectrum under such conditions is not straightforward and it is likely that the wind speed, the propagation speed and the spatial scale of the gale system coincidentally matched to enhance the freakish sea state at the accident's location.

\section{Conclusions}

The direct cause of a marine accident often remains unexplained. However, marine accidents do occur under certain sea states (e.g. Toffoli et al., 2005). As demonstrated in previous studies, a number of marine accidents were associated with narrowing of the directional spectrum (Tamura et al., 2009; In et al., 2009; Waseda et al., 2012). The narrowing of the spectrum can be visualized in a diagram of the directional spreading $\sigma_{\theta}$ and frequency peakedness $Q_{\mathrm{p}}$. Marine accidents tended to occur in the turning point of the trajectory in 

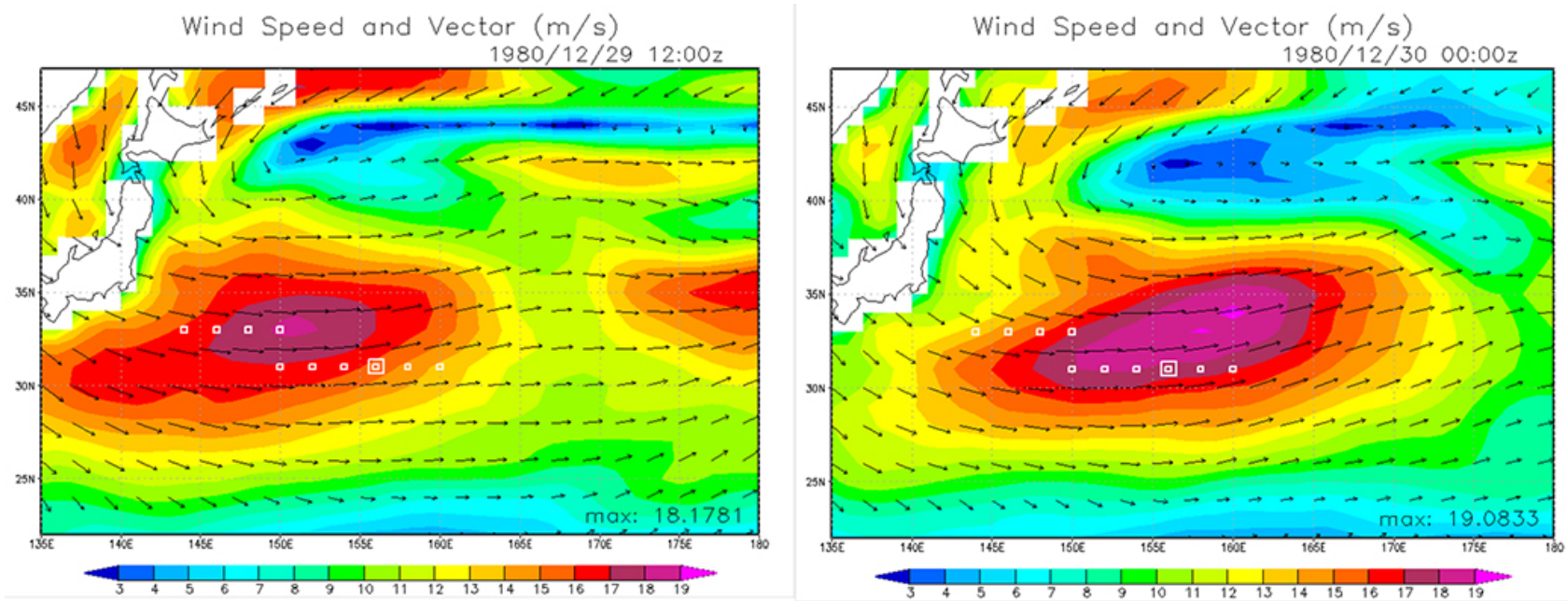

Fig. 12. Wind field evolution: $12 \mathrm{~h}$ before the accident (left) and at the time of the accident (right). The contour shading is the wind speed and the arrows indicate wind direction.

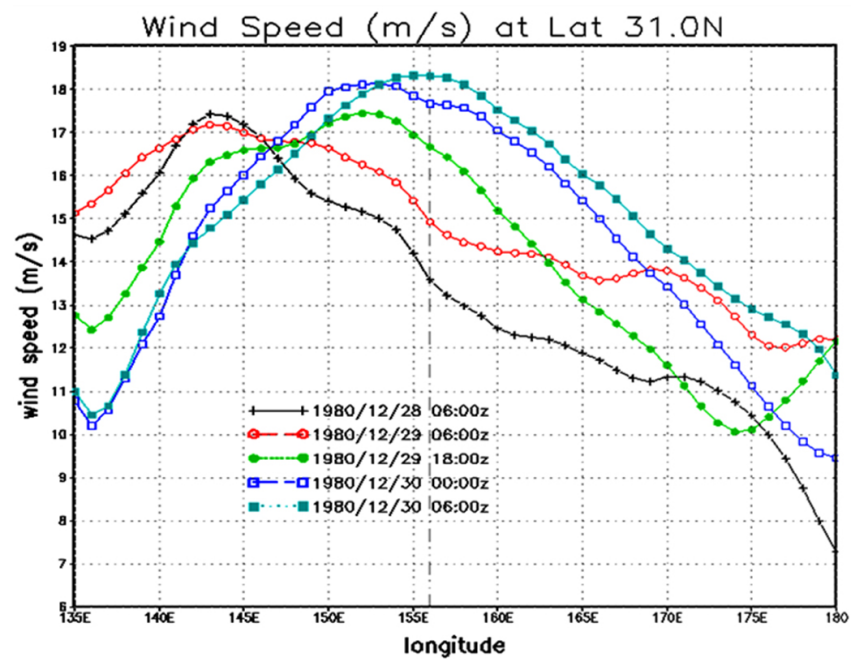

Fig. 13. Wind speed sections along $31^{\circ} \mathrm{N}$ from $135^{\circ}-180^{\circ} \mathrm{E}$ from 28 December 06:00 UTC to 30 December 06:00 UTC.

this domain. We called the $Q_{\mathrm{p}}$ and $\sigma_{\theta}$ diagram the freakishsea index. In this study, we have shown that the dangerous sea state can be well predicted with both DIA and SRIAM simulations. The response of the directional spectrum to changing wind condition is sensitive to the accuracy of the nonlinear interaction source term (Tamura et al., 2008). However, for operational use, the DIA is most commonly used. Therefore, the finding that the freakish-sea index is equally well predicted with DIA and SRIAM is good news for operational purposes. Of course, both are model results and ought to be validated by observations. However, the observations in this region are rather limited. The hindcast simulations of the Pacific Ocean with SRIAM and DIA were validated against available buoy observations by Tamura et al. (2010); it was

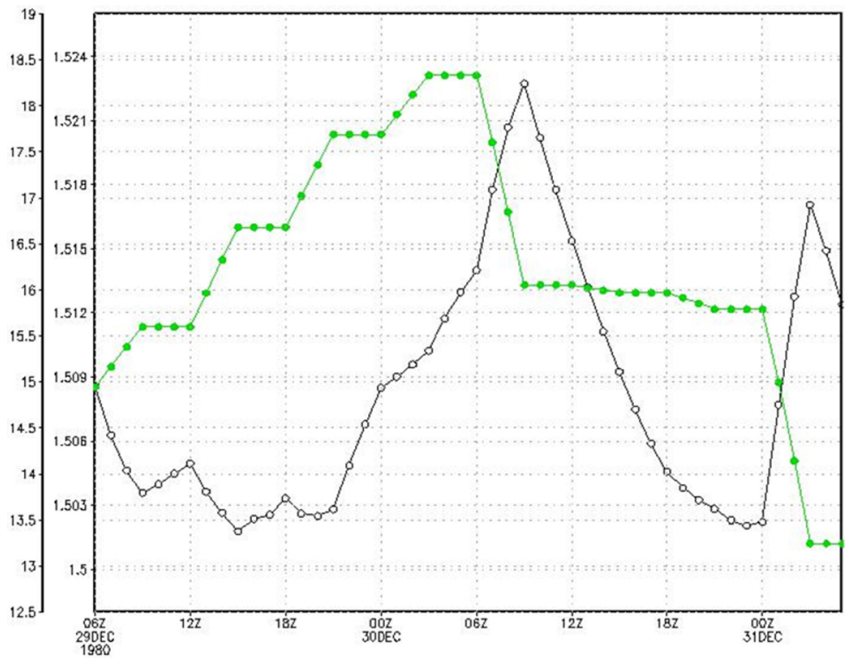

Fig. 14. Evolution of the exponent $\alpha$ (black line) and the wind speed (green line) $24 \mathrm{~h}$ before and after the accident. The horizontal axis is time in UTC and the vertical axes are the exponent $\alpha$ (ranging from around 1.5 to 1.525 ) and the wind speed (ranging from 12.5 to $\left.19 \mathrm{~m} \mathrm{~s}^{-1}\right)$.

shown that the energy is reproduced equally well while the peak period was better reproduced by SRIAM. Apart from such difference between models, a common shortcoming of the models is that the directional spectrum tends to be much broader than observations (Babanin et al., 2010). Therefore, the numerous freak-wave indices are quantitatively inaccurate when estimated from the wave model. What the $Q_{\mathrm{p}}$ and $\sigma_{\theta}$ diagram indicates is a much larger change of the spectral geometry as a result of meteorological forcing. On the physical aspect, the case study of the Onomichi-Maru incident revealed that a moving gale system is associated with 
the development of the freakish sea. While the spectral peak period remained relatively unchanged, the energy increased. As a result, the spectrum narrowed. The dynamics of such spectral development is yet to be understood and left for future study.

Acknowledgements. The authors are grateful for the three anonymous reviewers and the editors of the NHESS special edition for their constructive comments. The analysis presented in the Appendix developed from the suggestion of one of the reviewers. The first author thanks Takeshi Kinoshita and Hiroshi Tomita for their encouragement and criticism during the course of research. The work was partially supported by Grants-in-Aid for Scientific Research of the Japan Society for the Promotion of Science.

Edited by: E. Bitner-Gregersen

Reviewed by: five anonymous referees

\section{References}

Atsukawa, M.: Shōwa no kamikaze, Haruzeē Kantai ga sōgūshita taifūni tsuite, Ichikawa Gakuen Chigakuka Kishōshitsu, 1999 (in Japanese).

Babanin, A. V., Tsagareli, K. N., Young, I. R., and Walker, D. J., Numerical investigation of spectral evolution of wind waves, Part II: Dissipation term and evolution tests, J. Phys. Oceanogr., 40, 667-683, 2010.

Badulin, S. I., Babanin, A. V., Zakharov, V. E., and Resio, D.: Weakly turbulent laws of wind-wave growth, J. Fluid Mechan., 591, 339-378, 2007.

Berlitz, C.: The Dragon's Triangle, Wynwood Press, 1989.

Drury, B. and Clavin, T.: Halsey's Typhoon: The True Story of a Fighting Admiral, an Epic Storm, and an Untold Rescue, Grove Press, 2007.

Gagnaire-Renou, E., Benoit, M., and Badulin, S. I.: On weakly turbulent scaling of wind sea in simulations of fetch-limited growth, J. Fluid Mechan., 669, 178-213. 2011.

Goda Y.: Numerical experiments on wave statistics with spectral simulation, Report of National Institute for Land and Infrastructure Management, 9, 3-57, 1970.

Hasselmann, K.: On the non-linear energy transfer in a gravity-wave spectrum, J. Fluid Mech, 12, 481-500, 1962.

Hasselman, S., Hasselman, K., Allender, J. H., and Barnett, T. P.: Computations and Parameterizations of the Nonlinear Energy Transfer in a Gravity-Wave Spectrum, Part II: Parameterizations of the Nonlinear Energy Transfer for Application in Wave Models, J. Phys. Oceanogr., 15, 1378-1390, 1985.

In, K.: Research on high accuracy wave forecasting to ensure safety of the ship navigation, 2009, Master's thesis the Department of Environmental and Ocean Engineering, School of Engineering, the University of Tokyo, 2009.

In, K., Waseda, T., Kiyomatsu, K., Tamura, H., Miyazawa, Y., and Iyama, K.: Analysis of a marine accident and freak wave prediction with an operational wave model, Pros., 19th Int, Offshore and Polar Engineering Conf., ISOPE, Osaka, Japan, 3, 877-883, 2009.

Iyama, K.: Development of a wave forecasting system to predict freak wave occurrence, Master's thesis, the Department of En- vironmental and Ocean Engineering, School of Engineering, the University of Tokyo, 2007.

Janssen, P. A. E. M.: Nonlinear Four-Wave Interactions and Freak Waves, J. Phys. Oceanogr., 33, 863-884, 2003.

Kharif, C. and E. Pelinovsky: Physical mechanisms of the rogue wave phenomenon, Europ. J. Mech. B/Fluids, 22, 603-634, 2003.

Komatsu, K. and Masuda, A.: A New Scheme of Nonlinear Energy Transfer among Wind Waves: RIAM Method -Algorithm and Performance-, J. Phys. Oceanogr., 52, 509-537, 1996.

Kuik, A. J., Van Vledder, G. Ph., and Holthuijsen, L.: Amethod for the routine analysis of pitch-and-roll buoy wave data, J. Phys. Oceanogr., 18, 1020-1034, 1988.

Lamont-Smith, T. and Waseda, T.: Wind wave growth at short fetch, J. Phys. Oceanogr., 38, 1597-1606, 2008.

Mori, N. and Janssen, P. A. E. M.: Dependence of freak wave occurrence on kurtosis, Rogue Wave 2004 IFREMER, Brest, 2004.

Mori, N. and Janssen, P. A. E. M.: On kurtosis and occurrence probability of freak waves, J. Phys. Oceanogr., 36, 1471-1483, 2006.

Mori, N., Onorato, M., and Janssen, P. A.: On the estimation of the kurtosis in directional sea states for freak wave forecasting, J. Phys. Oceanogr., 41, 1484-1497, 2011.

Otsubo, H.: Wreckage offshore the Nozima Peninsula, Symposium on destruction of ships and marine structures, 1983 (in Japanese).

Onorato, M., A. R. Osborne, Serio, M., and Bertone, S.: Freak Waves in Random Oceanic Sea States, Phys. Rev. Lett., 86, 5831-5834, 2001.

Onorato, M., Osborne, A. R., and Serio, M.: Extreme wave events in directional, random oceanic sea states, Phys. Fluids, 14, 25-28, 2002.

Onorato, M., Osborne, A. R., Serio, M., Cavaleri, L., Brandini, C., and Stansberg, C. T.: Observation of stronglly nonGaussian statistics for random sea surface gravity waves in wave flume experiments, Phys. Rev. E, 70, 067302, doi:10.1103/PhysRevE.70.067302, 2004.

Onorato, M., Waseda, T., Toffoli, A., Cavaleri, L., Gramstad, O., Janssen, P. A. E. M., Kinoshita, T., Monbaliu, J., Mori, N., Osborne, A. R., Serio, M., Stansberg, C. T., Tamura, H., and Trulsen, K.: On the statistical properties of directional ocean waves: the role of the modulational instability in the formation of extreme events, Phys. Rev. Lett., 102, 114502, doi:10.1103/PhysRevLett.102.114502, 2009.

Soquet-Juglard, H., Dysthe, K., Trulsen, K., Krogstat, H. E., and Liu, J.: Probability distribution of surface gravity waves during spectral changes, J. Fluid Mech., 116, 207-225, 2005.

Tamura, H., Waseda, T., Miyazawa, Y., Komatsu, K.. CurrentInduced Modulation of the Ocean Wave Spectrum and the Role of Nonlinear Energy Transfer, J. Phys. Oceanogr., 38, 26622684, 2008.

Tamura, H., Waseda, T., and Miyazawa, Y., Freakish sea state and swell-windsea coupling: Numerical study of the Suwa-Maru incident, Geophys. Res. Lett., 36, L01607, doi:10.1029/2008GL036280, 2009.

Tamura, H., Waseda, T., and Miyazawa, Y.: Impact of nonlinear energy transfer on the wave field in Pacific hindcast experiments, J. Geophys. Res. Oc., (1978-2012) 115.C12., doi:10.1029/2009JC006014, 2010.

Toba, Y.: Local balance in the air-sea boundary processes, J. Oceanogr. Soc. Japan, 29, 209-220, 1973. 
Toffoli, A., Lefevre, J. M., Bitner-Gregersen, E., and Monbaliu, J., Towards the identification of warning criteria: Analysis of a ship accident database, Appl. Oc. Res., 27, 281-291, 2005.

Toffoli, A., Bitner-Gregersen, E., Onorato, M., and Babanin, A. V.: Wave crest and trough distributions in a broad-banded directional wave field, Oc. Engin., 35, 1784-1792, 2008.

Tolman, H. L.: User manual and system documentation of WAVEWATCH III version 2.22, NOAA/NWS/NCEP/MMAB Technical Note, 222, 133 pp., 2002.

Tomita, H.: ISSC 2009 I.1 Environment, Official Discusser, in: Proc. 17th International Ship and Offshore Structures Congress (ISSC), 3, Seoul, Korea, 2009.

Waseda, T.: Impact of directionality on the extreme wave occurrence in a discrete random wave system," 9th International Workshop on Wave Hindcasting and Forecasting, 2006.
Waseda, T., Kinoshita, T., and Tamura, H., Evolution of a Random Directional Wave and Freak Wave Occurrence, J. Phy. Oceanogr., 38, doi:10.1175/2008JPO4031.1, 2009.

Waseda, T., Hallerstig, M., Ozaki, K., and Tomita, H. Enhanced freak wave occurrence with narrow directional spectrum in the North Sea, Geophys. Res. Lett., 38, L13605, doi:10.1029/2011GL047779, 2011.

Waseda, T., Tamura, H., and Kinoshita, T.: Freakish sea index and sea states during ship accidents, J. Mar. Sci. Technol., 17, 305314, 2012.

Xiao, W., Liu, Y., Wu, G., and Yue, D. K.: Rogue wave occurrence and dynamics by direct simulations of nonlinear wave-field evolution, J. Fluid Mechan., 720, 357-392, 2013.

Yamamoto, Y., Otsubo, H., Iwai, Y., Watanabe, I., Kumano, A., Fujino, M., Fukasawa, T., Aoki, M., Ikeda, H., and Kuroiwa, T. Disastrous Damage of a Bulk Carrier due to Slamming, The lecture of The Society of Naval Architects of Japan in 1983, 1983. 


\section{Appendix A}

The wind waves under influence of local wind are considered to be in "local equilibrium" and, as proposed by Toba (1973), satisfies the following relationship: $\left(\frac{g H_{\mathrm{s}}}{u_{*}^{2}}\right)=$ $B^{1 / 2}\left(\frac{g T}{u_{*}}\right)^{3 / 2}$. Toba's three-halves law corresponds to the fetch laws: $\left(\frac{g H_{\mathrm{s}}}{u_{*}^{2}}\right) \propto\left(\frac{g F}{u_{*}}\right)^{1 / 2}$ and $\left(\frac{g H_{\mathrm{s}}}{u_{*}^{2}}\right) \propto\left(\frac{g F}{u_{*}}\right)^{1 / 3}$. It is known that the observed fetch laws do not necessarily have the same exponents (e.g. Lamont-Smith and Waseda, 2009 and references therein). Recently, in the framework of weakturbulence theory, the exponents of these relationships were shown to vary depending on the regimes of the fetch-limited growth (Gagnaire-Renouet al., 2011; Badulinet al., 2007). It is therefore not surprising that in an unstationary wind condition or when fetch is not well defined the wind sea does not satisfy the conventional laws. The exponent $\left(\frac{g H_{\mathrm{s}}}{u_{*}^{2}}\right)=$ $B^{1 / 2}\left(\frac{g T}{u_{*}}\right)^{\alpha}$ was estimated assuming a constant drag coefficient of 0.002 and $B=0.062$ (Fig. 14). Apparently, the exponent $\alpha$ is highly variable in time and depends largely on wind speed. The exponent $\alpha$ increased in the $12 \mathrm{~h}$ before the accident. The implication of this result, according to GagnaireRenou et al. (2011), may be that the wind sea before the accident tended to be "undersaturated". More work is vital. 